\title{
TNF- $\alpha$ Up-regulates Renal MIF Expression in Rat Crescentic Glomerulonephritis
}

\author{
Hui Y. Lan,* Niansheng Yang,* Christine Metz, ${ }^{\dagger}$ Wei Mu,* \\ Qing Song,* David J. Nikolic-Paterson,* Michael Bacher, ${ }^{\dagger}$ \\ Richard Bucala, ${ }^{\dagger}$ and Robert C. Atkins* \\ *Department of Nephrology, Monash Medical Centre, 246 Clayton \\ Road, Victoria 3168, Australia \\ tThe Picower Institute for Medical Research, 350 Community Drive, \\ Manhasset, New York 11030, U.S.A.
}

\begin{abstract}
Background: Macrophage migration inhibitory factor (MIF) is a potent proinflammatory mediator that participates in the pathogenesis of endotoxemia and experimental crescentic glomerulonephritis. However, very little is known about how MIF production is regulated in disease. We therefore examined whether tumor necrosis factor $\alpha$ (TNF- $\alpha$ ), a known inducer of MIF expression by macrophages in vitro, up-regulates local and systemic MIF expression in a macrophage-mediated rat model of crescentic glomerulonephritis.

Materials and Methods: Anti-glomerular basement membrane (GBM) glomerulonephritis was induced in groups of six primed rats. Animals were treated with 1 $\mathrm{mg} / \mathrm{kg}$ soluble TNF- $\alpha$ receptor (TNFbp) or saline from the time of disease induction until they were killed on Days 1, 7, or 14. Renal MIF expression was assessed by in situ hybridization, immunohistochemistry, and ELISA, and compared with macrophage accumulation and indices of renal damage.

Results: Although TNFbp treatment on Day 1 of the disease had only a partial effect upon the up-regulation
\end{abstract}

of glomerular MIF expression, on Days 7 to 14 it almost completely abrogated the increase in glomerular and interstitial MIF mRNA and protein expression. In addition, TNFbp treatment significantly inhibited MIF secretion by cultured glomeruli and reduced serum MIF levels. The inhibition of renal MIF expression was paralleled by a significant inhibition of glomerular and interstitial macrophage infiltration $(p<0.001$ versus saline treated), a significant suppression of renal injury (proteinuria and serum creatinine), and a marked reduction in histologic damage (glomerular hypercellularity, crescent formation, and interstitial fibrosis; all $p<0.01$ versus saline treated).

Conclusions: This study demonstrates for the first time that TNF- $\alpha$ up-regulates local MIF expression by both infiltrating macrophages and resident kidney cells in rat crescentic glomerulonephritis. In addition, TNF- $\alpha$ regulates systemic MIF production. Thus, TNF- $\alpha$, together with MIF, may play a pathological role in immunologically induced renal disease.

\section{INTRODUCTION}

Macrophage migration inhibitory factor (MIF) was originally described as a product of activated $T$ cells that inhibits the migration of macrophages in vitro $(1,2)$. Now, however, it is evident that MIF is not exclusively produced by $\mathrm{T}$ cells. Recent studies demonstrate that MIF is constitu-

Address correspondence and reprint requests to: Hui Y. Lan, Department of Nephrology, Monash Medical Centre, 246 Clayton Road, Clayton, Victoria 3168, Australia. tively expressed by a variety of cell types, including monocytes/macrophages, anterior pituitary cells, and renal tubular epithelial cells (3-5). Antibody-blocking studies have shown a key pathogenic role for increased MIF production in experimental endotoxemia (6). Glucocorticoids at low levels up-regulate MIF expression via a counterregulatory mechanism, whereby MIF can then act to override the glucocorticoid effects $(7,8)$. In addition, in vitro studies have shown that the proinflammatory cytokines tumor necrosis factor 
$\alpha$ (TNF- $\alpha)$ and interferon $\gamma$ (IFN- $\gamma$ ) up-regulate macrophage MIF production, and that conversely, MIF induces production of TNF- $\alpha$ and IFN- $\gamma(4,9)$, which suggests the presence of an amplifying proinflammatory loop response. However, there is little in vivo evidence for the functional significance of this amplification pathway.

We have recently shown that MIF production is markedly up-regulated in a rat model of crescentic glomerulonephritis. Increased MIF expression correlated significantly with macrophage infiltration, loss of renal function, and development of renal lesions, including glomerular crescent formation (5). Since TNF- $\alpha$ has been implicated in the pathogenesis of this disease $(10,11)$, we sought to determine whether TNF- $\alpha$ is a physiological inducer of MIF production during the disease process. This was examined by blocking the action of TNF- $\alpha$ in rat crescentic glomerulonephritis by treatment with TNF binding protein (TNFbp), a soluble form of recombinant human TNF- $\alpha$ receptor type 1, and by assessing the effect upon MIF expression and renal injury.

\section{MATERIALS AND METHODS}

\section{Nephrotoxic Serum}

Rabbit anti-rat glomerular basement membrane (GBM) nephrotoxic serum was raised by repeated immunization of New Zealand white rabbits with purified, particulate rat GBM. The sera was pooled, decomplemented at $56^{\circ} \mathrm{C}$ for 30 min, absorbed against rat red blood cells at $4^{\circ} \mathrm{C}$ overnight, and stored at $-20^{\circ} \mathrm{C}$.

\section{TNF Binding Protein}

A dimeric form of recombinant human TNF- $\alpha$ receptor type I, termed the TNF binding protein (TNFbp), was generously supplied by Amgen, Colorado.

\section{Experimental Design}

Accelerated anti-GBM glomerulonephritis was induced in inbred male Sprague-Dawley rats $(150-200 \mathrm{~g})$ as previously described $(12,13)$. Briefly, animals were immunized s.c. with $5 \mathrm{mg}$ normal rabbit IgG in Freund's complete adjuvant and injected i.v. with $10 \mathrm{ml} / \mathrm{kg}$ rabbit anti-rat GBM serum (12.5 $\mathrm{mg} \mathrm{IgG} / \mathrm{ml}) 5$ days later (termed Day 0). Groups of six rats were injected intraperitoneally with $1 \mathrm{mg} / \mathrm{kg}$ body weight of TNFbp every second day from $2 \mathrm{hr}$ before administration of anti-GBM serum until being killed on Days 1,7 , or 14. Groups of six control animals had the same schedule, but received saline (vehicle) in place of TNFbp. In addition, one group of six normal rats was also studied. The study was approved by the Animal Experimentation Ethics Committee of Monash Medical Centre.

\section{Renal Function}

Blood samples and 24-hr urine collections were taken on Days $0,1,7$, and 14. Urinary protein excretion was determined with the Manual Ponceau Red method. Serum creatinine was measured with the standard Jaffe rate reaction (Alkaline picrate). All analyses were performed at the Department of Biochemistry, Monash Medical Centre.

\section{Histopathology}

Kidney tissues for histological examination were fixed in $10 \%$ formalin and $4-\mu \mathrm{m}$ paraffin sections were stained with hematoxylin and eosin or periodic acid-Shiff (PAS). Coded slides were assessed as previously described $(12,13)$. Twenty glomerular cross sections per animal were examined under high power to determine glomerular hypercellularity $(0-3)$ and the percentage of glomeruli with crescent formation, while the degree of cortical tubulointerstitial fibrosis $(0-4)$ was also determined.

\section{Immunohistochemistry}

Single and double immunostaining was performed on $4-\mu \mathrm{m}$ paraffin sections of formalinfixed kidney with a newly developed method of microwave-based, multiple immunoenzymatic staining (14). Briefly, sections were dewaxed, placed in $0.01 \mathrm{M}$ sodium citrate buffer, $\mathrm{pH}$ 6.0, and heated for $2 \times 5 \mathrm{~min}$ in a microwave oven at $2450 \mathrm{MHz} / 800 \mathrm{~W}$. This procedure facilitates retrieval of cytoplasmic antigens. Sections were then incubated with mouse EDI monoclonal antibody (MAb) (anti-CD68, which recognizes monocytes and macrophages) (15) or mouse anti-human MIF MAb, which also recognizes rat MIF (16), using a three-layer peroxidase antiperoxidase (PAP) staining protocol, and developed with 3,3-diaminobenzidine, thereby giving a brown product. For double immunostaining, 
sections were microwave heated for a second time after completion of the three-layer PAP staining with the EDI MAb to denature bound immunoglobulin molecules and prevent antibody cross-reactivity. Sections were then labeled with the anti-MIF MAb by means of a threelayer alkaline phosphatase-anti-alkaline phosphatase (APAAP) method and developed with Fast Blue BB Base (Sigma Chemical Co., St. Louis, MO), which yielded a blue product. Sections were counterstained with PAS reagent without hematoxylin and coverslipped in an aqueous mounting medium. An isotypematched mouse antibody 73.5 against human $\mathrm{CD} 45 \mathrm{R}$ was used as the negative control.

\section{In Situ Hybridization}

A 420 bp Xba 1/Bam Hl fragment of mouse MIF cDNA in the Bluescript SK + vector (Stratagene, La Jolla, CA) (17), which is highly homologous to the rat nucleotide sequence (18), was used to prepare sense and antisense MIF cRNA probes labeled with digoxigenin-11-UTP by in vitro transcription according to the manufacturer's protocol (Boehringer Mannheim, Mannheim, Germany). The incorporation of digoxigeninlabeled nucleotides was assayed by spotting serial dilutions of probes onto Hybond nylon membrane (Amersham, Little Chalfont, Buckinghamshire, U.K.) and detecting the bound probe with alkaline phosphatase-conjugated Fab fragments of anti-digoxigenin IgG with 4-nitroblue tetrazolium chloride and $\mathrm{X}$-phosphate substrates according to the manufacturer's instructions (Boehringer Mannheim). Only probes detectable at a concentration of $0.1 \mathrm{pg} / \mu \mathrm{l}$ or lower were used.

In situ hybridization was performed on $4-\mu \mathrm{m}$ paraffin sections of formalin-fixed tissue by using a newly developed microwave-based technique (19). After dewaxing, sections were treated with a microwave oven for $2 \times 5 \mathrm{~min}$ as outlined above, incubated with $0.2 \mathrm{M} \mathrm{HCl}$ for $15 \mathrm{~min}$, followed by $1 \%$ Triton $X-100$ for $15 \mathrm{~min}$, and then digested for $20 \mathrm{~min}$ with $10 \mu \mathrm{g} / \mathrm{ml}$ proteinase- $\mathrm{K}$ at $37^{\circ} \mathrm{C}$ (Boehringer Mannheim). Sections then were washed in $2 \times \mathrm{SSC}$, prehybridized, and then hybridized with $0.3 \mathrm{ng} / \mu$ l DIG-labeled sense or anti-sense cRNA probe overnight at $42^{\circ} \mathrm{C}$ in a hybridization buffer containing $50 \%$ deionized formamide, $4 \times$ SSC, $2 \times$ Denhardt's solution, $1 \mathrm{mg} / \mathrm{ml}$ salmon sperm DNA (Sigma), and $1 \mathrm{mg} / \mathrm{ml}$ yeast tRNA. Sections were washed in $0.1 \times \mathrm{SSC}$ at $42^{\circ} \mathrm{C}$ and the hybridized probe detected by means of alkaline phosphatase-conjugated sheep anti-digoxigenin IgG and color development with NBT/X-phosphate. The sections were counterstained with PAS and mounted in an aqueous medium. Some sections were subsequently microwave oven treated and used for three-layer PAP staining with the anti-MIF or EDI MAb, as described above.

\section{Quantitation of in Situ Hybridization and Immunohistochemistry Staining}

The quantitation of positively stained cells in tissue sections was performed as previously described (5). Briefly, the number of cells labeled by the MIF cRNA probe or anti-MIF MAb were counted in at least 50 consecutive glomerular cross sections (gcs) in each animal. In doublestained sections, the number of $\mathrm{EDI}^{+}, \mathrm{MIF}^{+}$, and $\mathrm{EDI}^{+} \mathrm{MIF}^{+}$cells was counted in 50 glomerular cross sections. Macrophage accumulation within the tubulointerstitium was assessed by counting $\mathrm{EDI}^{+}$cells in 20 consecutive high-power fields $(\times 40)$ by means of a $0.02 \mathrm{~mm}^{2}$ graticule fitted into the eyepiece of the microscope. Counting progressed from the outer cortex to the inner cortex, avoiding only large vessels and glomeruli. In addition, the number of labeled tubules was scored in at least 1000 consecutive cortical tubular cross sections. Data from groups of six animals are expressed as the mean \pm standard error of the mean (SEM) per glomerular cross section or per square millimeter $\left(\mathrm{mm}^{2}\right)$.

\section{MIF Secretion by Cultured Glomeruli}

Glomeruli were purified by differential sieving. Briefly, a half kidney from each animal was placed in RPMI 1640 with $5 \%$ fetal calf serum (FCS), diced finely, gently pressed through a $250-\mu \mathrm{m}$ wire mesh, and poured through a $106-\mu \mathrm{m}$ and then a $75-\mu \mathrm{m}$ wire mesh. Glomeruli remaining on the top of a $75-\mu \mathrm{m}$ mesh were washed extensively with RPMI $/ 5 \%$ FCS and collected. Isolated glomeruli were $>95 \%$ pure as assessed by phase-contrast microscopy. Glomeruli were cultured at 3000 glomeruli/ml in RPMI $1640 / 5 \%$ FCS for $24 \mathrm{hr}$ and the supernatant was harvested. The concentration of MIF in supernatant samples was quantitated by a sandwich ELISA (7).

\section{Serum MIF Levels}

Serum MIF levels were assessed by Western blotting since the presence of rat serum proteins 
TABLE 1. Effect of TNFbp treatment on renal injury in anti-GBM disease

\begin{tabular}{lccccc}
\hline & $\begin{array}{c}\text { Proteinuria } \\
(\mathbf{m g} / \mathbf{2 4} \mathbf{~ h r})\end{array}$ & $\begin{array}{c}\text { Serum } \\
\text { Creatinine } \\
(\boldsymbol{\mu} \mathbf{m o l} / \mathbf{L})\end{array}$ & $\begin{array}{c}\text { Glomerular } \\
\text { Hypercellularity } \\
\mathbf{( 0 - 3 )}\end{array}$ & $\begin{array}{c}\text { Glomerular } \\
\text { Crescents } \\
(\%)\end{array}$ & $\begin{array}{c}\text { Interstitial } \\
\text { Fibrosis } \\
(\mathbf{0}-\mathbf{4})\end{array}$ \\
\hline Normal & $9 \pm 2$ & $42.7 \pm 1.0$ & 0 & 0 & 0 \\
Saline treated & $65 \pm 22^{a}$ & $47.8 \pm 6.0$ & $0.82 \pm 0.10$ & 0 & $0.8 \pm 0.2$ \\
Day 1 & $204 \pm 22^{c}$ & $59.3 \pm 4.4^{b}$ & $1.30 \pm 0.17$ & $10.3 \pm 2.1$ & $2.3 \pm 0.3$ \\
Day 7 & $288 \pm 14^{c}$ & $67.2 \pm 2.4^{c}$ & $1.40 \pm 0.06$ & $17.3 \pm 2.6$ & $3.2 \pm 0.3$ \\
Day 14 & $43 \pm 4^{a}$ & $49.0 \pm 4.4$ & $0.71 \pm 0.07$ & $0.3 \pm 0.3$ & $0.5 \pm 0.2$ \\
TNFbp treated & $125 \pm 18^{c, f}$ & $47.2 \pm 5.1$ & $0.99 \pm 0.12$ & $0.3 \pm 0.2^{f}$ & $1.2 \pm 0.2^{d}$ \\
Day 1 & $190 \pm 16^{c, f}$ & $46.0 \pm 1.8^{e}$ & $0.89 \pm 0.07^{e}$ & $0.9 \pm 0.3^{f}$ & $1.2 \pm 0.2^{e}$ \\
Day 7 & & & & & \\
Day 14 & & & & & \\
\hline
\end{tabular}

Data shown as mean \pm SEM. ${ }^{a} p<0.05,{ }^{b} p<0.01 ;{ }^{c} p<0.001$ versus normal; ${ }^{d} p<0.05 ;{ }^{e} p<0.01,{ }^{f} p<0.001$ compared to time-matched saline-treated animals.

interfered with the MIF ELISA. Five-microliter serum samples from all animals were resolved by SDS polyacrylamide gel electrophoresis, blotted onto nitrocellulose membrane, incubated sequentially with rabbit anti-murine MIF polyclonal antibody and horse radish peroxidaseconjugated goat anti-rabbit antibody, and developed with chloronaphthol/ $\mathrm{H}_{2} \mathrm{O}_{2}$, as previously described (4). Recombinant MIF was used as a control to compare levels of MIF expression.

\section{Statistical Analyses}

One-way analysis of variance (ANOVA) from the Complete Statistical Analysis program (CSS, Statsoft, Tulsa, OK, USA) was used to analyze differences in MIF expression, macrophage accumulation, and renal functional in normal animals, TNFbp-treated, and saline-treated antiGBM disease. Differences in histology were compared by the nonparametric Mann-Whitney U test.

\section{RESULTS}

\section{Renal Function and Histopathology}

The induction of anti-GBM disease in salinetreated animals resulted in severe proteinuria and a significant increase in serum creatinine levels (Table 1). Saline-treated animals showed significant glomerular hypercellularity and crescent formation plus marked interstitial fibrosis on Day 14 of anti-GBM disease. In contrast, TN-
Fbp treatment caused a significant reduction in proteinuria and maintained normal levels of serum creatinine (Table 1). Consistent with these measurements, TNFbp-treated animals showed only mild glomerular hypercellularity and interstitial fibrosis, whereas crescent formation was almost entirely abolished.

\section{Glomerular MIF Expression and Macrophage Accumulation}

In situ hybridization and immunohistochemistry staining showed that a small number of glomerular visceral and parietal epithelial cells constitutively expressed MIF mRNA (3-10 cells/gcs) and protein ( $0-3$ cells/gcs) (Fig. la, b). The induction of anti-GBM disease in saline-treated animals caused a rapid increase in the number of glomerular cells expressing MIF mRNA and protein on Day 1, and this was further increased on Days 7 and 14 (Figs. 1 and 2). This up-regulation of glomerular MIF expression was paralleled by macrophage accumulation over the 14-day period (Fig. 1c). TNFbp treatment caused only a partial reduction in glomerular MIF expression on Day 1 of disease compared with expression in salinetreated animals, and this did not affect glomerular macrophage accumulation (Fig. la-c). However, TNFbp treatment almost completely prevented any further increase in MIF mRNA or protein expression during the rest of the course of the disease, which was paralleled by inhibition of glomerular macrophage accumulation (Figs. 1 and 2). 
Glomerulus

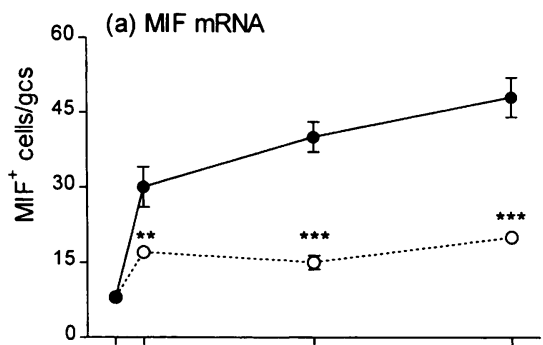

(b) MIF protein

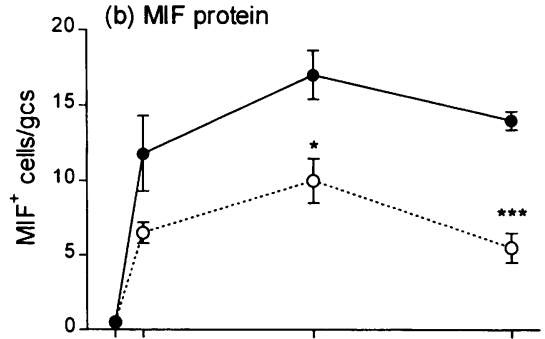

(c) Macrophages

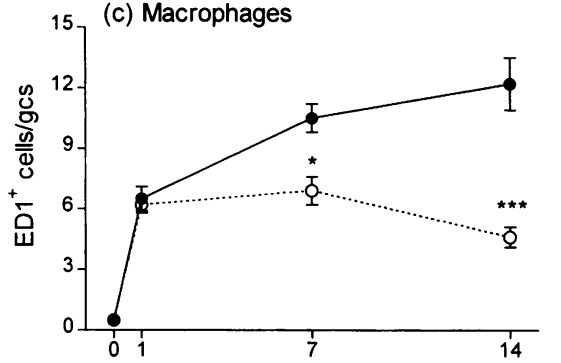

Tubulointerstitium

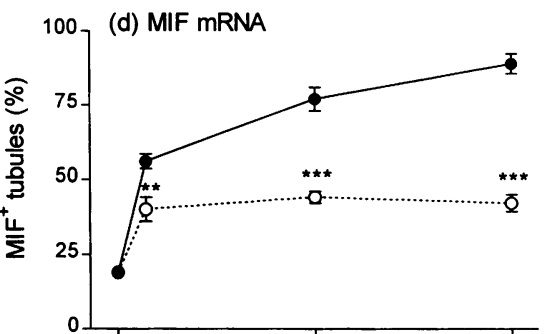

(e) MIF protein
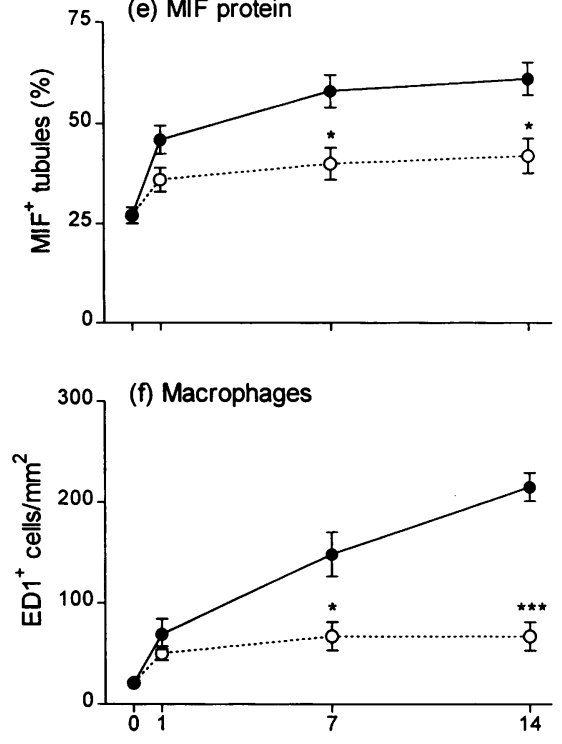

FIG. 1. TNFbp treatment inhibits glomerular and tubular MIF expression and macrophage accumulation in rat anti-GBM glomerulonephritis

(a) Quantitation of glomerular MIF mRNA expression by in situ hybidization; (b) quantitation of glomerular MIF protein expression by immunohistochemistry; (c) quantitation of glomerular ED1-positive macrophages; (d) quantitation of tubular MIF mRNA expression by in situ hybidization; (e) quantitation of tubular MIF protein expression by immunohistochemistry; and (f) quantitation of EDl-positive macrophages within the tubulointerstitium. Saline-treated animals are represented by solid lines and closed circles, TNFbp-treated animals, by dotted lines and open circles. Data are expressed as the mean \pm SEM from groups of six animals. ${ }^{*} p<$ $0.05,{ }^{* *} p<0.01$, and ${ }^{* * *} p<$ 0.001 , compared with salinetreated animals.

Since TNF- $\alpha$ is known to induce macrophage MIF production in vitro, we used double immunohistochemistry staining to examine the number of macrophages expressing MIF mRNA and protein in anti-GBM disease (Fig. 2). Quantitation of double staining demonstrated that the number of glomerular $\mathrm{EDI}^{+} \mathrm{MIF}^{+}$macrophages was significantly inhibited by TNFbp treatment (Fig. 3). While this was due in part to an overall reduction in the number of glomerular macrophages seen with TNFbp treatment, there was also a reduction in the percentage of glomerular macrophages positive for MIF (25.8 \pm 4.5 versus
$58.0 \pm 3.4 \%$ in TNFbp- and saline-treated animals, respectively; $p<0.001$ ).

Glomerular MIF production was also quantitated by measuring MIF secretion by purified glomeruli during a 24-hr culture period. Substantial levels of MIF were secreted by glomeruli cultured from normal rat kidney (Fig. 4). This was significantly increased on Day 14 of anti-GBM disease in saline-treated animals. TNFbp treatment caused a significant reduction in glomerular MIF secretion compared with that in saline-treated animals. In addition, TNFbp treatment produced a trend towards a reduction in the basal level of

FIG. 2. TNFbp treatment inhibits glomerular and tubular MIF expression and macrophage accumulation in rat anti-GBM glomerulonephritis

Combined in situ hybridization and immunohistochemistry show MIF mRNA expression (blue) by intrinsic kidney cells and by ED1-positive macrophages (brown) on Day 7 of disease with (a) saline or (b) TNFbp treatment. Double immunohistochemistry shows colocalization of strong MIF expression (blue) and EDl-positive macrophages (brown) on Day 14 of disease with (c) saline or (d) TNFbp treatment. Macrophages (brown) expressing MIF mRNA or protein are indicated by arrowheads. Strong MIF expression and the development of crescent formation and tubulitis are seen. Sections were counterstained with PAS minus haematoxylin. Original magnification, $\times 400$. 

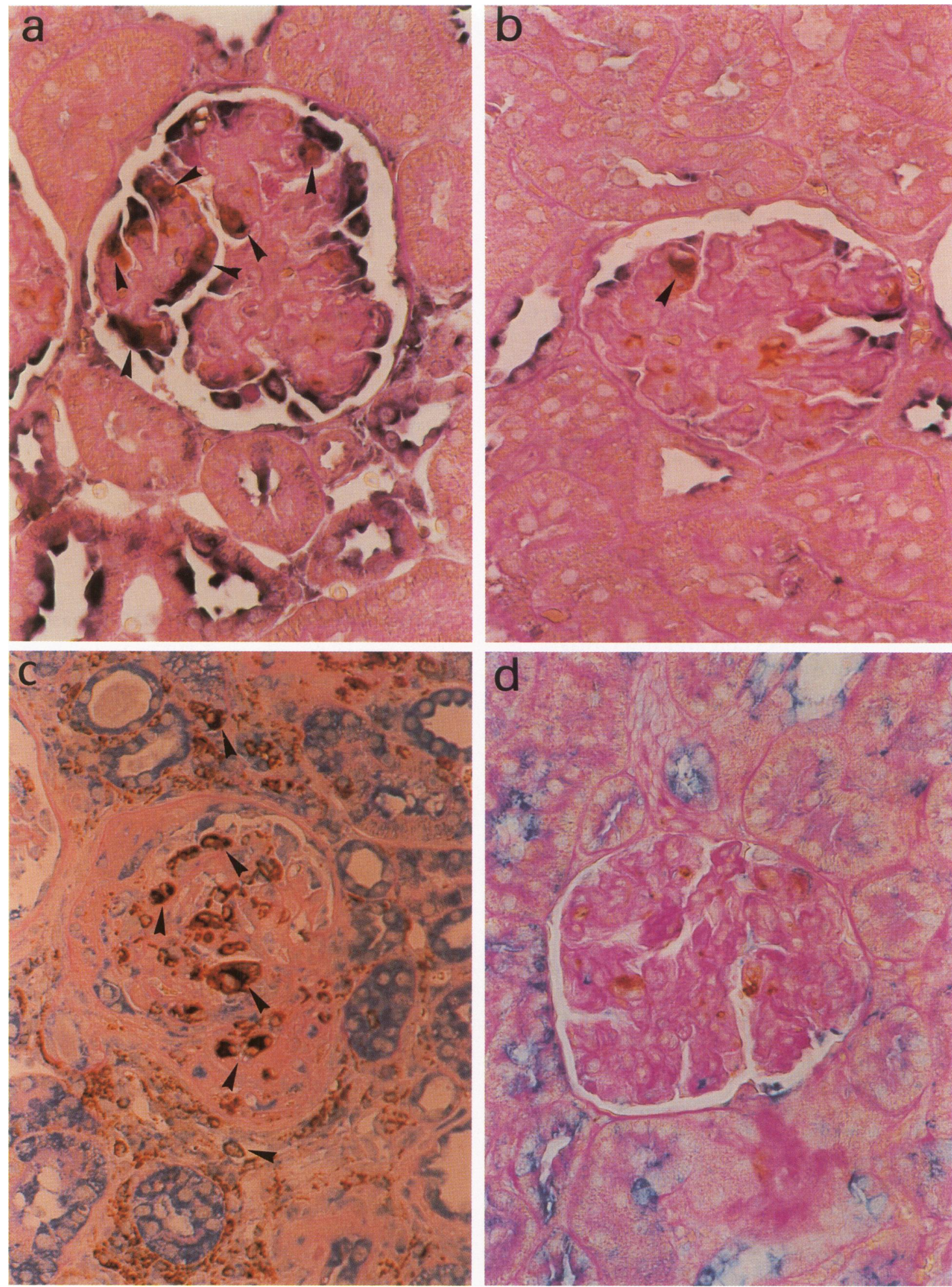


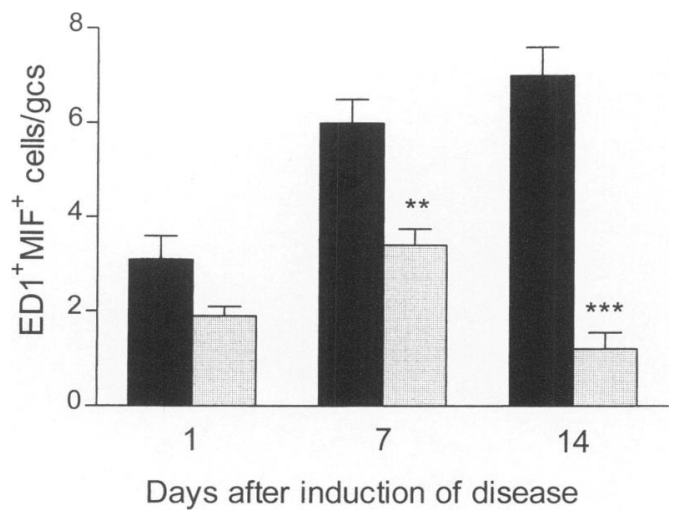

FIG. 3. TNFbp treatment inhibits macrophage MIF expression in anti-GBM glomerulonephritis

Quantitation of double immunohistochemistry staining shows the number of $\mathrm{MIF}^{+} \mathrm{EDI}^{+}$macrophages in saline- (solid bars) and TNFbp- (dotted bars) treated animals. Each bar represents groups of six animals (mean $\pm \mathrm{SEM}) .{ }^{* \star} p<0.01,{ }^{* \star *} p<0.001$.

glomerular MIF secretion seen in normal rats, but this did not reach statistical significance.

\section{Tubular MIF Expression and Interstitial Macrophage Accumulation}

Tubular epithelial cells are the main source of MIF in normal kidney, with up to $30 \%$ of cortical tubules being positive for MIF mRNA and protein expression. As in glomeruli, there was a rapid up-regulation in tubular MIF mRNA and protein on Day 1 of saline-treated anti-GBM disease, which was further increased over the course of the disease (Figs. 1 and 2a, c). A significant interstitial macrophage infiltration occurred in parallel with the increase in MIF expression (Fig. 1f). Tubular MIF expression was prominent within focal tubulointerstitial lesions and the development of tubulitis. Double-labeling studies showed that most interstitial EDI ${ }^{+}$ macrophages were present in and around tubulointerstitial lesions with strong tubular MIF expression (Fig. 2a, c).

Consistent with the effects seen in glomeruli, TNFbp treatment caused only a partial reduction in tubular MIF expression on Day 1, but it prevented any further increase in tubular MIF mRNA and protein expression over Days 7 and 14 of the disease (Fig. ld, e). This was associated with a marked suppression of both interstitial macrophage infiltration and a complete inhibition of tubulointerstitial damage (Table 1, Figs. 1 and 2).

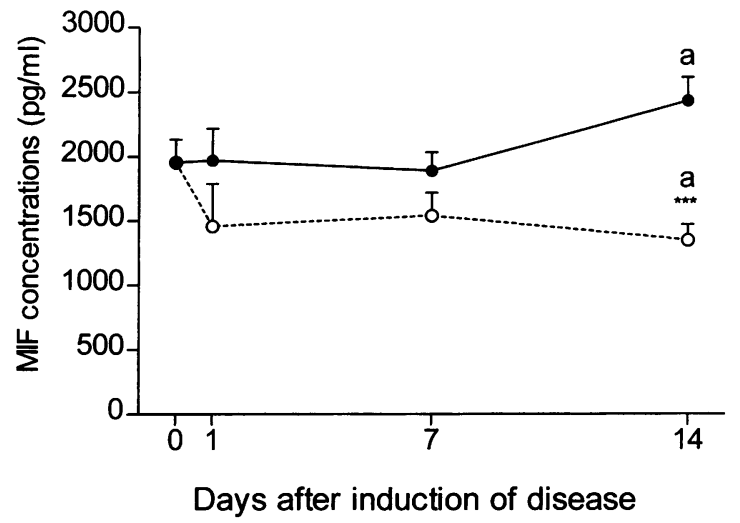

FIG. 4. TNFbp treatment inhibits glomerular MIF section in rat anti-GBM glomerulonephritis

Secretion of MIF by cultured glomeruli over a 24-hr period was quantitated by ELISA in normal rats (Day 0 ) and in saline- (solid circles) and TNFbp(open circles, dotted line) treated animals. Data are expressed as the mean \pm SEM from groups of six animals. ${ }^{* *} p<0.001$, compared with saline-treated animals; a, $p<0.05$, compared with normal animals (Day 0).

\section{Serum MIF Levels in Anti-GBM Disease}

To compare the effects of TNFbp treatment on systemic MIF production during anti-GBM disease, we examined serum MIF levels by Western blotting. MIF was detected in normal rat serum and MIF levels were substantially increased during the course of saline-treated anti-GBM disease (Fig. 5). In contrast, TNFbp treatment resulted in undetectable levels of serum MIF on Day 1 and markedly reduced serum MIF levels over Days 3 to 14 , compared with saline-treated animals.

\section{DISCUSSION}

This study is the first to demonstrate that TNF- $\alpha$ up-regulates both local and systemic MIF production in an immunologically induced disease. In previous studies, we described an excellent correlation between up-regulation of renal MIF expression and the progression of renal injury in rat crescentic glomerulonephritis (5). Furthermore, it has recently been reported that treatment of this disease model with a neutralizing anti-MIF antibody substantially blocks macrophage accumulation and progressive renal injury, demonstrating a pathogenic role for MIF in macrophage-mediated glomerulonephritis (20). Blockade of TNF- $\alpha$ action by administration of 


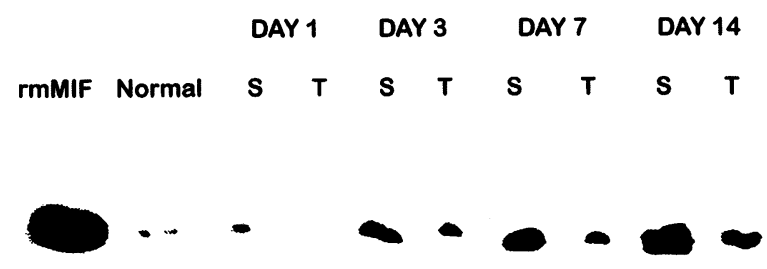

FIG. 5. TNFbp treatment reduces serum MIF levels during the anti-GBM glomerulonephritis Through Western blot analysis, the presence of serum MIF protein was detected in normal rats, which is the same size as the recombinant protein. TNFbp treatment caused a marked reduction in the level of serum MIF protein over the entire disease time course, compared with that in saline-treated animals.

the TNFbp caused a profound suppression of renal MIF production, which was associated with inhibition of macrophage infiltration, reduction in renal injury, prevention of renal function impairment, and histological damage. This confirms the importance of TNF- $\alpha$ in the development of anti-GBM glomerulonephritis $(10,11)$. Furthermore, it suggests that up-regulation of MIF production is a pathological manifestation of progressive renal functional and histologic injury, including glomerular crescent formation. However, TNF- $\alpha$ may also act to promote macrophage accumulation through other mechanisms. For example, TNF- $\alpha$ can induce expression of interleukin-1, monocyte chemoattractant protein-1, and intercellular adhesion molecule-1, all of which have been shown to contribute to leukocytic infiltration and subsequent renal injury in rat anti-GBM disease $(13,21,22)$.

The ability of TNFbp treatment to inhibit macrophage MIF mRNA and protein expression during crescentic glomerulonephritis confirms the relevance of in vitro studies in which TNF- $\alpha$ was found to induce macrophage MIF production (4). In addition, the ability of TNFbp to inhibit MIF mRNA and protein expression by intrinsic renal cells, such as glomerular and tubular epithelial cells, demonstrates that TNF- $\alpha$ can also induce MIF expression in cell types other than leukocytes. Furthermore, TNFbp treatment reduced serum MIF levels. Although the cellular source of circulating MIF has yet to be identified, this study has shown that TNF- $\alpha$ up-regulates the systemic MIF response in inflammatory disease. It should be pointed out that while TNFbp treatment suppressed both local and systemic MIF expression, levels of MIF expression were not reduced below those seen in normal animals, demonstrating that TNF- $\alpha$ does not regulate constitutive MIF expression.

These data support the existence of an amplification loop between TNF- $\alpha$ and MIF that exerts a potent proinflammatory effect in vivo. This pathway may operate through the transcription factor NF- $\kappa$ B. Expression of the TNF- $\alpha$ gene is strongly induced by NF- $\kappa \mathrm{B}$, and TNF- $\alpha$ stimulation of target cells results in activation of NF- $\kappa$ B $(23,24)$. Furthermore, an NF- $\kappa B$ site has been identified within the promoter of the mouse MIF gene (17). Thus, it is feasible that both TNF- $\alpha$ and MIF act to mutually up-regulate each other through the activation of NF- $\kappa \mathrm{B}$. This may also be the mechanism of the counter-regulatory relationship between MIF and glucocorticoids, since glucocorticoids have recently been shown to exert their anti-inflammatory action by inhibiting activation of NF- $\kappa B$ (25). Nevertheless, the presence of endocrine-responsive elements within the MIF gene promoter also indicates that the regulation of MIF transcription may be more complex (17).

In summary, this study has demonstrated that TNF- $\alpha$-induced up-regulation of local and systemic MIF expression may be one of the important mechanisms mediating renal injury in experimental crescentic glomerulonephritis. Furthermore, this provides the first in vivo evidence that TNF- $\alpha$ and MIF act together in a proinflammatory amplification loop in the pathogenesis of immune/inflammatory disease.

\section{ACKNOWLEDGMENTS}

This study was supported by NH \& MRC (950912 and 960106) and NIH (AI-21359) grants.

\section{REFERENCES}

1. David JR. (1966) Delayed hypersensitivity in vitro: Its mediation by cell-free substances formed by lymphoid cell-antigen interaction. Proc. Natl. Acad. Sci. U.S.A. 56: 72-77.

2. Bloom BR, Bennett B. (1966) Mechanism of a reaction in vitro associated with delayedtype hypersensitivity. Science 153: 80-82.

3. Nishno T, Bernhagen J, Shijki H, Calandra T, Dohl K, Bucala R. (1995) Localization of macrophage migration inhibitory factor (MIF) to secretory granules within the corticotrophic and thyrotrophic cells of the pituitary gland. Mol. Med. 1: 781-788.

4. Calandra T, Bernhagen J, Mitchell RA, Bu- 
cala R. (1994) The macrophage is an important and previously unrecognized source of macrophage migration inhibitory factor. $J$. Exp. Med. 179: 1895-1902.

5. Lan HY, Mu W, Yang N, et al. (1996) De novo renal expression of macrophage migration inhibitory factor (MIF) during the development of rat crescentic glomerulonephritis. Am. J. Pathol. 149: 1119-1127.

6. Bernhagen J, Calandra T, Mitchell RA, et al. (1993) MIF is a pituitary-derived cytokine that potentiates lethal endotoxaemia. Nature 365: 756-759.

7. Calandra $\mathrm{T}$, Bernhagen $\mathrm{J}$, Metz $\mathrm{CN}$, et al. (1995) MIF as a glucocorticoid-induced modulator of cytokine production. Nature 376: 68-71.

8. Bacher M, Metz CN, Calandra T, et al. (1996) An essential regulatory role for macrophage migration inhibitory factor in T-cell activation. Proc. Natl. Acad. Sci. U.S.A. 93: 7849-7854.

9. Pozzi LA, Weiser WY. (1992) Human recombinant migration inhibitory factor activates human macrophages to kill tumor cells. Cell Immunol. 145: 372-379.

10. Hruby ZW, Shirota K, Jothy S, Lowry RP. (1991) Antiserum against tumor necrosis factor-alpha and a protease inhibitor reduce immune glomerular injury. Kidney Int. 40: 43-51.

11. Baud L, Fouqueray B, Philipp C. (1994) Involvement of tumor necrosis factor-alpha in glomerular injury. Springer Semin. Immunopathol. 16: 53-61.

12. Lan HY, Paterson DJ, Atkins RC. (1991) Initiation and evolution of interstitial leukocytic infiltration in experimental glomerulonephritis. Kidney Int. 40: 425-433.

13. Lan HY, Nikolic-Paterson DJ, Mu W, Vannice JL, Atkins RC. (1995) Interleukin-1 receptor antagonist halts the progression of established crescentic glomerulonephritis in the rat. Kidney Int. 47: 1303-1309.

14. Lan HY, Mu W, Nikolic-Paterson DJ, Atkins RC. (1995) A novel, simple, reliable, and sensitive method for multiple immunoenzyme staining: Use of microwave oven heating to block antibody crossreactivity and retrieve antigens. J. Histochem. Cytochem. 43: 97-102.

15. Dijkstra CD, Dopp EA, Joling P, Kraal G. (1985) The heterogeneity of mononuclear phagocytes in lymphoid organs: Distinct macrophage subpopulations in the rat recognized by monoclonal antibodies ED1, ED2 and ED3. Immunology 54: 589-599.
16. Bacher M, Meinhardt A, Lan HY, et al. (1997) MIF expression in experimentallyinduced endotoxemia. Am. J. Pathol. 150: 235246.

17. Mitchell R, Bacher M, Bernhagen J, Pushkarskaya T, Seldin MF, Bucala R. (1995) Cloning and characterization of the gene for mouse macrophage migration inhibitory factor (MIF). J. Immunol. 154: 3863-3870.

18. Sakai M, Nishihira J, Hibiya Y, Koyama Y, Nishi S. (1994) Glutathione binding rat liver $13 \mathrm{k}$ protein is the homologue of the macrophage migration inhibitory factor. Biochem. Mol. Biol. Int. 33: 439-446.

19. Lan HY, Mu W, Ng Y-Y, Nikolic-Paterson DJ, Atkins RC. (1996) A simple, reliable, and sensitive method of nonradioactive in situ hybridization: Use of microwave heating to improve hybridization efficiency and preserve tissue morphology. J. Histochem. Cytochem. 44: 281-287.

20. Lan HY, Bacher M, Mu W, et al. (1996) Blockade of macrophage migration inhibitory factor (MIF) inhibits rat crescentic glomerulonephritis (GN). (abstract) J. Am. Soc. Nephrol. 7: 1707.

21. Nishikawa K, Guo YJ, Miyasaka M, et al. (1993) Antibodies to intercellular adhesion molecule $1 /$ lymphocyte function-associated antigen 1 prevent crescent formation in rat autoimmune glomerulonephritis. J. Exp. Med. 177: 667-677.

22. Tang WW, Qi M, Warren JS. (1996) Monocyte chemoattractant protein 1 mediates glomerular macrophage infiltration in antiGBM Ab GN. Kidney Int. 50: 665-671.

23. Beg AA, Finco TS, Nantermet PV, Baldwin AS Jr. (1993) Tumor necrosis factor and interleukin-1 lead to phosphorylation and loss of I kappa B alpha: a mechanism for NFkappa B activation. Mol. Cell Biol. 13: 33013310.

24. Trede NS, Tsytsykova AV, Chatila T, Goldfeld AE, Geha RS. (1995) Transcriptional activation of the human TNF-alpha promoter by superantigen in human monocytic cells: Role of NF-kappa B. J. Immunol. 155: 902-908.

25. Auphan N, DiDonato JA, Rosette C, Helmberg A, Karin M. (1995) Immunosuppression by glucocorticoids: Inhibition of NFkappa B activity through induction of I kappa B synthesis. Science 270: 286-290. 